\title{
Örnek Bir Çeltik İşletmesinde Kullanılması Gereken Tarım Makinaları Büyüklükleri ve Sayılarının Doğrusal Programlama Yöntemi ile Tespit(
}

\author{
Gıyasetti'n ÇIÇEK ${ }^{1}$ \\ Selçuk ARIN ${ }^{1}$
}

GeHş Tarihi: $24,04.2003$

\begin{abstract}
Öıêt; Çeltik günümüzde buğaaydan sonra en geniş eklm alanına ve üretimine sahip orundur. BOton tarımsal ürünlerde olduğu glbı çelO üretiminde de birim alandan elde edılen ürün miktarının artırılmasında tarım makinalarının önemli etkisi vardır. Tarımsal işletmecilik problemlerinin çöz.ümünde yaygın olarak kullanılan en önemfi yöntemlerden biriside doğrusal programlama yöntemıdir. Çeltik üretiminde doğrusal programlama yöntemini kullanarak tarım makfnalan masrafını minimiz.e edecek modellerin kurulması ve bilgisayar yardımı ile bu modellerin çöz.omu sonucunda büyük oranda ekonomiklik sağlanacaktır. Bu çalışmada çeltik üretiminde yaygın olarak kullanılan tarım makinaları ele alınmış, Microsoft Excel ve QSB paket programları kullanılarak doğrusal programlama yardımı ile makina masrafinı mlnimize edecek makine setintn saptanması amaçlanmıştır.
\end{abstract}

Anahtar Kelimeler: tarım makinaları, çeltik, doğrusal programlama

\section{Determination of Number and Size of Farm Machinery That is Required to Use at A Model P ddy Management by Linear Programming}

\begin{abstract}
Nowadays, padaly is the most important crop that has the widest production amount and area following wheat. Agricuitural machfnery have important effects on increasing of 'yield as in other crops. Unear programming method that is commonly used farm manag.ement problems is one of the most rmportant methods. Forming of models that will minimiz.e costs of agricultura machir,ery by usfng linear programmfng meVıod and solving this models by using computer Will provlded ecorıomy at paddy pröduction, in this research machfnes that are used widely in paddy productlorı were laken up. it was aimed !hat determination of machinery set !hat min 1 m1zes of machinery cost by using Microsoft Excel and QSB computer programs.
\end{abstract}

Key Words: agricullural machinery, paddy, linear programming

\section{Giriş}

Hızlı nüfus artışı karşısında. yeterli olmayan gıda maddeleri üretimi dünyamızda her geçen gün giderek büyüyen beslenme sorununa neden olmaktadır. Bu durum ülkeleri tarımlarına daha fazla önem vermeye ve tarımsal Oretfmlerini artırmak için daha yoğun çalışmaya zorlamaktadır. Bazı ülkeler bu soruna var olan tarım alanıatını genişleterek çözüm ararlarken tarım alanlan sınırlı olan ülkelerde birim alandan daha çok ürün almayı amaçlayan ileri üretim teknolojileri uygulamalarına ağırlık vermektedirler (Ulusoy ve Özbaydur 1995).

insan iş verimini gellştirereK üretimin ekonomik düzeyini artırmak için tarımsal üretimde teknik tarım uygulamalarının gereğt, kuHanılan her türlü mekanik araçların tasarım, yaptm, geliştirme, uygulama deneyleri, paza ama, işletme, bakım, onarım ve yayımı ile llglll tüm hizmetler olarak tarınılad@rnız tarımsal mekanizasyonun belirli bir amaca yönelik optimum planlamasının yapılabtlmesi için temel ver1terin sağlanarak sağlıklı olarak derlenmesi ile bunlarm yaygın ve hızlı kullanımının gerçekleştirilmesine yönelik düzenlemelerin yapılmasına bilyOk. gereksinim vardır. Bunda edinme ve enerji maliyetfnln her geçen gün artması nedeniyle tarımsal mekan1zasyon giderlerinin işletmenin genel giderleri içerisindeki yüksek payının rolü büyüktür (Bölül<oğlU ve ark. 1994).

- Doktora Tezl'nden hazırlanmıştır.

Trakya Üniv. Ziraat Fak. Tarım Makinaları Bölümü-Tekırdağ
Tarımda modernizasyonun sağlanmasında doğru makine seçimi en önemli kıstaslardan biridir. Tarımsal işletmeler makine seçimi yaparken genellikle teknik ve ekonomi şar(ları göz önüne almaktadırlar. Makine seçiminin optimize edilmesi için hava koşulları. işlem aşamaları, üretim alanı ve makine masrafları gibi bileşenlerin etkilerJnin hesaplanması gerekmektedir \{Parmarve ark. 1996).

Günümüzde buğdaydan sonra en geniş ekim alanına sahip çeltik üretiminde de birim alandan elde edilen ürün miktarının artırımasında tarım makinelerinin önemi büyüktür. Kısıtlı zaman içerisinde miktar ve kalitenin en az masrafla artırılması gerekmektedir. Bunun için tarım mkirıelerinden birim alan içinde en az masrafla yararlanmayı sağlayacak programlar kullanılmalıdır. Tür1<iye'deki çeltik ekim alanı ve üretim miktarı göz önüne alınırsa bunun önemi daha iyi anlaşılabilir (Çizelge 'I).

\section{Materyal ve Yöntem}

Modelde çeltik tarımında yaygın olarak kullanılan tarım makinelerine yer verilmiştir.. Çeşitli büyOklUklere sahip bu makineler Çizelge 2'de verildiği gibidir. 

programlama

Çizelge 1. Türkiye Çeltik Ekim Alanı ve Üretim Miktan (Anonim 2000)

\begin{tabular}{|l|c|c|}
\hline II & Ekim alanı (ha) & Uretim miktarı (ton) \\
\hline Edirne & 30954 & 172559 \\
Bursa & 729 & 4376 \\
Çorum & 5934 & 40017 \\
Sinop & 4645 & 27150 \\
Samsun & 6915 & 41493 \\
Kastamonu & 1630 & 8250 \\
Çanakkale & 3766 & 29468 \\
Balıkesir & 2781 & 46369 \\
Mardin & 362 & 800 \\
Diyarbakır & 147 & 4790 \\
\hline Toplam & 57863 & 375272 \\
\hline
\end{tabular}

Çizelge 2 Çeltik Uretiminde Kullanilan Traktör ve Tanm Makinelerinin Büyüklükleri (Anonim 2002b)

\begin{tabular}{|l|c|}
\hline Makine & Makine büyüklü̆ğ (m) \\
\hline Pulluk (2 gövdeli) & 0,6 \\
Pulluk (3 gövdeli) & 0,9 \\
Pulluk (4 gövdeli) & 1,2 \\
Pulluk (5 gövdeli) & 1,5 \\
\hline Goble diskaro & 2 \\
& 3 \\
& 4 \\
\hline Lazerli toprak tesv. mak. & 3,5 \\
& 4 \\
& 4,5 \\
& 5 \\
\hline Kombikürüm & 2 \\
& 2,5 \\
& 3 \\
\hline Dişli tırmık & 2 \\
& 2,5 \\
\hline Ekim makinesi & 3 \\
\hline Biçerdöver & \\
\hline Traktör (kW) & 100 \\
& 88 \\
& 80 \\
& 74 \\
& 66 \\
\hline
\end{tabular}

Modelde çeltik tarımında yaygın olarak kullanılan tarım makinelerine yer verilmiştir. Çeşitli büyüklüklere sahip bu makineler Çizelge 2 'de verildiği gibidir.

Bu çalışmada geliştirilen model, çeltik üretimi yapan işletmelerde işletme büyüklüğü, çalışılabilir zaman aralıkları, alet ve makinelerin iş başarıları ve çeki güçleri ile farklı güçte traktörlerle kullanılabilen tarım alet ve makinelerin yillık maliyetlerine bağlı olarak makine seçimi yapmaktır.

Modelde, kullanılabilecek makinelerin maliyetleri, iş başarıları ve çeki güçleri önceden tespit edilerek, makine, traktör ve iş gücü gereksinimi göz önüne alınmakta ve sonuç olarak üretim dönemindeki çalıșılabilir zamana bağlı olarak minimum maliyeti veren makine seti elde edilmektedir.

Model için gerekli veriler beş başlık altında toplanmıştır (Bölükoğlu ve ark. 1994).
Işletme büyüklüğü: Modelde örnek işletmenin 400 ha alanda çeltik üretimi yaptığı kabul edilmiştir.

Tarla işlemleri ve bu işlemlerde kullanılan tarım makineleri büyüklüklerî: Çeltik üretiminde izlenen mekanizasyon zinciri ve kullanılan makineler aşağıdaki gibidir.

Sürüm (pulluk), 1, tırmiklama (goble diskaro), arazi tesviyesi (lazerli tesviye mak.), 2. tirmıklama (kombikürüm), 3. tırmıklama (dişli tırmık), ekim (savurmalı ekim mak.) ve hasat (biçerdöver). Ilaçlama ve gübreleme elle yapıldığı için modelde yer verilmemiştir. Modelde ayrica yörede yaygın olarak kullanılan 7 adet traktör ele alınmıştır (Çizelge 2).

Makinelere ait temel işletmecilik verileri: Ișletmecilik verileri olarak makinelerin iş genişlikleri ve ilerleme hızlarına bağlı olan iş başarıları ele alınmıştır. Makinelerin çeki gücü gereksinimleri literatürlerden elde edilmiştir (Çiçek 1997. Arın ve ark. 2001). Iş başarıları ise aşağıdaki formülden hesaplanmıştır (Keskin ve Erdoğan 1992).

$$
S=3,6^{*} B^{*} V^{*} K
$$

S: Makinenin iş başarısi (da/h)

$\mathrm{B}$ : Makinenin iş genişliği $(\mathrm{m})$

V: Makinenin çalışma hızı (m/s)

k: Çalışma zamanından yararlanma katsayısı (\%)

Yıllık makine masraflarının hesaplanmasında kullanılan veriler: Makine giderlerinin hesaplanmasında satın alma fiyatları, faiz oranları, saatlik ve yıllık ömür, tamir ve bakım faktörleri, işçilik ücreti ve yakıt fiyatı değişkenleri oluşturmaktadır. Bu değişkenler ile amortisman, faiz, muhafaza, bakım, tamir ve yakıt-yağ masraflari hesaplanmiştir (Dinçer 1976).

Amortisman masrafi:

$$
\mathrm{a}=\frac{A-R}{T}
$$

A: Makinenin satın alma bedeli $(€)$

$R$ : Makinenin hurda değeri $\left(0,1^{*} A\right)$

$\mathrm{T}$ : Makinenin ömrü (yıl)

Faiz masrafı:

$$
\mathrm{f}=\frac{(A+R) * i}{2}
$$

i. Yilik faiz oranı (\%) (Ziraat bankası tarım makinelerine Ekim 2002'de \% 90 faiz oranı uygulamıştır).

Muhafaza masrafi:

$$
\mathrm{m}=\frac{0,9 * A}{100}(\text { Tarim makineleri için })
$$




$$
\mathrm{m}=\frac{1,3 * A}{100} \text { (Traktör için) }
$$

Tamir masrafi:

$$
\mathrm{t}=\frac{A^{*} r}{n}
$$

r: Tamir faktörü

$\mathrm{n}$ : Makinenin ömrü $(\mathrm{h})$

Bakım masrafi:

$$
b=w^{*} L
$$

w : Bakım faktörü

$\mathrm{L}$ : Işçilik ücreti $(€ / \mathrm{h})$

Yakıt ve yağ masrafı:

$$
\mathrm{y}_{0}=0,103^{*} \mathrm{~N}^{*} \mathrm{~K}_{\mathrm{m}}
$$

$\mathrm{N}$ : Kullanilan traktör gücü $(\mathrm{kW})$

$K_{m}$ : Yakıt fiyatı $(€ / l t)$

Her periyotta çalışılabilir zaman aralıkları: Bir makinenin sınırlı zaman içerisinde gereken işlemi yapabilmesi onun büyüklüğü ile doğrudan ilgilidir. Modelde sınırlı zaman aralığında belirtilen tarımsal işi yapabilecek en düşük masraflı makinenin seçilmesi amaçlanmıştır.

Bir çok üründe olduğu gibi çeltiğin üretiminde de bir tarımsal işlemin bitmesi diğer bir tarımsal işlemin başlaması demektir. Çeltik üretiminde herhangi bir tarımsal işlem, önceki işlemin bittiği tarihten daha önce başlamakta ve o işlemden birkaç gün sonra bitirilmektedir. Ipsala ilçesinde periyotlara göre çalışılabilir saat sayıları Çizelge 3'te verildiği gibidir.

Doğrusal programlamada kullanılan amaç fonksiyonu ve kısıtların belirlenmesinde yararlanılan matematiksel model üç bölümden oluşmaktadır (Agrawal ve Heady 1972, Işık 1992, Sındır ve Evcim 1989, Yakut 1985).

1. Amaç fonksiyonu: Minimum gideri sağlamak amacıyla karar değişkenlerinin etkilerinin karşılaştırıldığı amaç fonksiyonudur.

$$
\mathrm{Z}_{\min }=\sum_{j=1}^{n} C_{j} . X_{j}
$$

Çizelge 3. Periyotlara Göre Çalışılabilir Saat Sayıları(Anonim 2002a)

\begin{tabular}{|l|c|}
\hline Periyot & Çalışılabilir saat (h) \\
\hline Eylül & 166 \\
Ekim & 163 \\
Geç Mart & 124 \\
Erken Nisan & 105 \\
Geç Nisan & 113 \\
Erken Mayıs & 119 \\
Geç Mayıs & 96 \\
\hline
\end{tabular}

\section{$Z_{\text {min }}$ : Amaç fonksiyonu}

$\mathrm{n}$ : İşlem sayısı

$\mathrm{C}_{\mathrm{j}}$ j j işlemindeki makine masrafı ( $\left.€ / \mathrm{ha}\right)$

$\mathrm{X}_{\mathrm{j}}$ : j işlemindeki alan miktarı (ha)

2. Kısıtlayıcı fonksiyonlar: Kısıt denklemleri 5 grup altında toplanmıştır.

a) Alan kısıtı: Bu kısıt hasat edilen alanın toplam üretim alanı değerine eşit olması gereğinden kaynaklanan kısıttır.

$$
\sum_{j=1}^{n} X_{i j}^{*}=\mathrm{A}
$$

i: Periyot sayısı

A: Işletmenin üretim alanı (ha)

Xij: i periyodunda yapılan $\mathrm{j}$ işleminin alan miktarı (ha)

b) Işlemlerin ardışımı kısıtı: Her işlemin yapıldığı alan bir önceki işlemin yapıldığı alana eşit veya küçük olmalıdır.

$$
\sum_{j=1}^{n} X_{i(j+1)} \leq \sum_{j=1}^{n} X_{i j}
$$

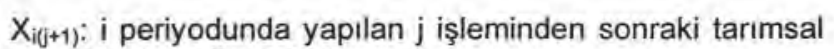
işlemin alan miktarı (ha)

c) Traktör kısıtı: Her çalışma periyodunda, tüm işlemler için gereken traktör zamanı, o periyottaki kullanılabilir traktör zamanını aşmamalıdır.

$$
\sum_{j=1}^{n} Q_{i j} \cdot X_{i j} \leq \mathrm{D}_{\mathrm{i}} \cdot \mathrm{X}_{\mathrm{T}}
$$

$Q_{i j}$ : i periyodundaki j işlemi için gerek duyulan traktör zamanı ( $\mathrm{h} / \mathrm{ha}$ )

$D_{i}:$ i periyodunda çalıșılabilir zaman (h)

$\mathrm{X}_{\mathrm{T}}$ : Traktör sayısı

d) Makine kısıtı: Her işlem için gereken makine zamanı, o periyottaki kullanılabilir makine zamanını aşmamalıdır.

$$
\sum_{j=1}^{n} P_{i j}, X_{i j} \leq \mathrm{D}_{\mathrm{i}} \cdot \mathrm{X}_{\mathrm{M}}
$$

$P_{i j}$ i periyodundaki $\mathrm{j}$ işlemi için gerek duyulan makine zamanı (h/ha)

$\mathrm{X}_{\mathrm{M}}$ : Makine sayısı

e) Işçilik kısıtı: Gereken işçilik zamanı, periyottaki kullanılabilir işçilik zamanını aşmamalıdır.

$$
\sum_{j=1}^{n} R_{i j}, X_{i j} \leq \mathrm{D}_{i} \cdot \mathrm{X}_{0}
$$

$\mathrm{R}_{\mathrm{ij}}$ : i periyodundaki j işlemi için gerek duyulan işçilik zamanı (h/ha)

$\mathrm{X}_{\mathrm{o}}$ : İşçi sayısı 
Model için gerekli veriler Microsoft Excel bilgisayar programına yüklenerek amaç fonksiyonu ve kısıt denklemleri elde edilmiştir. Elde edilen bu denklemlerin QSB paket programına girilmesi ile çeltik üretiminde kullanılacak makine büyüklükleri ve sayıları ondalıkı olarak tespit edilmiştir. Ondalıklı olarak elde edilen sayılar belirtilen işlemin yapılabileceği ve minimum masrafın sağlanabileceği şekilde tam sayıya çevrilerek 400 ha'lık tarım arazisine sahip bir çeltik ișletmesinin elinde bulundurması gereken minimum makine masrafını sağlayacak makine büyüklükleri ve sayıları elde edilmiştir.

\section{Bulgular ve Tartışma}

Celtik üretiminde kullanılan makinelerin satın alma bedelleri ve hesaplamalar sonucunda bulunan yillik maliyetleri Çizelge 4'te verildiği gibidir.

Modelin çözümünden sonra minimum makine masrafını veren makine sayıları ve bu makinelerin hangi periyotta ne kadar alan ișlediği Çizelge 5 'te verildiği gibidir.

Çizelge 5 'te görüldüğü gibi işletmede 1 adet $100 \mathrm{~kW}$, 1 adet $66 \mathrm{~kW}$ ve 6 adet $52 \mathrm{~kW}$ traktörün bulundurulması

Çizelge 4. Çeltik Üretiminde Kullanılan Traktör ve Tarım Makinelerinin Satın Alma Bedelleri ve Yıllık Maliyetleri

\begin{tabular}{|c|c|c|c|}
\hline Makine & Makine büyüklüğü $(\mathrm{m})$ & Satın alma bedeli $(€)$ & Yillik maliyet (€/yil) \\
\hline Pulluk (2 gövdeli) & 0,6 & 250 & 200 \\
\hline Pulluk (3 gövdeli) & 0,9 & 375 & 285 \\
\hline Pulluk (4 gövdeli) & 1,2 & 450 & 338 \\
\hline Pulluk (5 gövdeli) & 1,5 & 630 & 458 \\
\hline \multirow[t]{3}{*}{ Goble diskaro } & 2 & 1700 & 1004 \\
\hline & 3 & 2500 & 1476 \\
\hline & 4 & 2800 & 1652 \\
\hline \multirow[t]{4}{*}{ Lazerli toprak tes. mak. } & 3,5 & 18700 & 10837 \\
\hline & 4 & 19100 & 11046 \\
\hline & 4,5 & 22000 & 12693 \\
\hline & 5 & 25000 & 14391 \\
\hline \multirow[t]{3}{*}{ Kombikürüm } & 2 & 500 & 331 \\
\hline & 2,5 & 800 & 531 \\
\hline & 3 & 1100 & 724 \\
\hline \multirow[t]{3}{*}{ Dişli tırmık } & 2 & 150 & 94 \\
\hline & 2,5 & 190 & 118 \\
\hline & 3 & 250 & 153 \\
\hline Ekim makinesi & & 600 & 378 \\
\hline Biçerdöver & & 150000 & 96725 \\
\hline \multirow[t]{7}{*}{ Traktör (kW) } & 100 & 60000 & 40450 \\
\hline & $88=$ & 56000 & 37770 \\
\hline & 80 & 55000 & 37100 \\
\hline & 74 & 41000 & 27720 \\
\hline & 66 & 15750 & 10803 \\
\hline & 60 & 23600 & 16062 \\
\hline & 52 & 6900 & 4873 \\
\hline
\end{tabular}

Çizelge 5. Minimum Makine Masrafını Sağlayacak Makine Büyüklükleri ve Sayılan

\begin{tabular}{|c|c|c|c|c|}
\hline Makine & Makine büyüklüğū & Makine sayisı & Periyot & Ișlenen alan(ha) \\
\hline Pulluk & $\begin{array}{l}3 \text { gövdeli } \\
4 \text { gövdeli }\end{array}$ & $\begin{array}{l}2 \\
5\end{array}$ & $\begin{array}{l}3 \\
4 \\
3 \\
3 \\
4 \\
4 \\
5 \\
5\end{array}$ & $\begin{array}{l}24,72(52 \mathrm{~kW} \text { ile) } \\
19(52 \mathrm{~kW} \text { ile) } \\
34,25(66 \mathrm{~kW} \text { ile) } \\
102,69(52 \mathrm{~kW} \text { ile }) \\
29(66 \mathrm{~kW} \text { ile) } \\
86,95(52 \mathrm{~kW} \text { ile) } \\
31,26(66 \mathrm{~kW} \text { ile) } \\
72,14(52 \mathrm{~kW} \text { ile })\end{array}$ \\
\hline Goble diskaro & $4 \mathrm{~m}$ & 1 & $\begin{array}{l}3 \\
4 \\
5\end{array}$ & $\begin{array}{l}152,81 \text { (52 kW ile) } \\
143,84(52 \mathrm{~kW} \text { ile) } \\
103,35(52 \mathrm{~kW} \text { ile) }\end{array}$ \\
\hline Lazerli tesviye mak. & $5 \mathrm{~m}$ & 1 & $\begin{array}{l}3 \\
4 \\
5\end{array}$ & $\begin{array}{l}149,4(100 \mathrm{~kW} \text { ile }) \\
114,45(100 \mathrm{~kW} \text { ile }) \\
136,15(100 \mathrm{~kW} \text { ile })\end{array}$ \\
\hline Kombikürüm & $\begin{array}{l}2 \mathrm{~m} \\
2,5 \mathrm{~m}\end{array}$ & $\begin{array}{l}3 \\
2\end{array}$ & $\begin{array}{l}6 \\
6 \\
5 \\
6\end{array}$ & $\begin{array}{l}6,84(66 \mathrm{~kW} \text { ile) } \\
126,49(52 \mathrm{~kW} \text { ile) } \\
129,88(52 \mathrm{~kW} \text { ile }) \\
136,78(52 \mathrm{~kW} \text { ile })\end{array}$ \\
\hline Dişli tırmık & $3 \mathrm{~m}$ & 2 & $\begin{array}{l}5 \\
6\end{array}$ & $\begin{array}{l}43,28(52 \mathrm{~kW} \text { ile }) \\
356,72(52 \mathrm{~kW} \text { ile })\end{array}$ \\
\hline Ekim mak. & & 2 & 7 & 400 (52 kW ile) \\
\hline Biçerdöver & & 2 & $\begin{array}{l}1 \\
2 \\
\end{array}$ & $\begin{array}{l}238,85(52 \mathrm{~kW} \text { ile) } \\
161,15(52 \mathrm{~kW} \text { ile) }\end{array}$ \\
\hline Traktör & $\begin{array}{l}100 \mathrm{~kW} \\
66 \mathrm{~kW} \\
52 \mathrm{~kW}\end{array}$ & $\begin{array}{l}1 \\
1 \\
6 \\
\end{array}$ & & \\
\hline Iş̧̧i & & 8 & & \\
\hline
\end{tabular}


yeterli olmaktadır. Sürúm işlemi için 2 adet 3 gövdeli, 5 adet 4 gövdeli pulluk, 1 . turmiklama için 1 adet 4 m'lik goble diskaro, tesviye için 1 adet 5 m'lik lazerli tesviye makinesi, 2. ve 3 . tırmıklama için 3 adet 2 m'lik ve 2 adet 2,5 m'lik kombikürüm ile 2 adet 3 m'lik dișli tırmık, 2 adet ekim makinesi, 2 adet biçerdöver ve son olarak tüm işlemlerin yapılabilmesi için 8 adet işçiye gereksinim olmaktadir.

Hangi makinenin hangi periyotta hangi traktör ile ne kadarlık alan işlemesi gerektiği çizelgede belirtildiği gibidir.

Modelin çözümü sonucunda işletmenin yıllık makine masrafi 658419,9 €/yil olmaktadır. Bulunan masrafın \% 70 ini sabit masraflar oluşturdug̃u için çok yưksek bir rakam ortaya çıkmaktadır. Masrafın bủyủk bölümünü sabit masrafların oluşturduğunun belirtilmesi çiftçiler açısından daha anlaşılır olacaktır.

\section{Sonuç}

Elde edilen sonuçiar gerçek işletmeler ile karşılaştırıldığında, çeltik tarımını büyük alanlarda yapan işletme sahiplerinin gereğinden fazla sayıda ve büyüklükte makine ve traktör kullandıkları söylenebilir:

Günümüzde elle çeltik üretimi yapmak pahalı olmakta, kısıtlı zaman dolayısıyla ișler yetișememekte ve makineli üretime göre daha az verim alınmaktadır. Bu nedenle küçük işletmeler satın alma bedelleri yüksek olan makineleri satın alamadıkları için ya bu makineleri kiralama yoluna veya arazilerini bũyük işletmelere kiraya verme yoluna gitmelidirler.

Çeşitli büyüklüklerdeki çeltik işletmeleri için yapilan hesaplamalarda ortalama \%20'lik bir masraf azalması meydana geldiği tespit edilmiștir. Bu ise $658420 € / 400$ ha masraf için $329,2 € /$ ha anlamina gelmektedir. Ulkemizdeki bütün çeltik alanları göz önüne alındığında toplam 19054 $286 €$ masraf azalması meydana gelmektedir. Böylelikle çeltik işletmelerinin üretimde kullanacakları makine seçiminde doğrusal programlama yardımı ile en az masrafı verecek olan makine setini tespit etmeleri ve bunu uygulamaları ile hem kendi işletmeleri hem de ülke ekonomisi için büyük bir kazanç sağlanacağı açıkça görülmektedir.

\section{Kaynaklar}

Agrawal, R. C. and E. O. Heady, 1972. Operations Research Metods for Agricultural Decisions. The lowa State University Pres, AMES. USA.

Anonim, 2000. Tarım if Múdürlükleri ve Celtik Komisyonları Kayitları.

Anonim, 2002a. Devlet Meteoroloji Iş̧leri Genel Müdürlüğù, 10 Yillık Ipsala İlçesi Meteorolojik Verileri. Ankara.

Anonim, 2002b. Tarım ve Köyișleri Bakanlığı, Ipsala Tanım Ilcçe Müdürlüğu 2002 Verileri. Ipsala.
Arın, S., E. Kahya ve G. Çiçek, 2001. Trakya Yöresinde Kullanilan Tanm Makineieri Ișletmeciligi Veri Tabanınin Bilgisayar Ortaminda Hazırlanmasi. Tarımda Bilișim Teknolojileri 4. Sempozyumu. Kahramanmaraș Sütçü İmam Universitesi. 2001. Kahramanmaras.

Bölükoğlu, H. I. Girgin, G. Yüksel, A. Darga ve A. Yaltırık, 1994. Tarım Makinelerinin Seçimine Yonelik Veri Tabanının Oluşturulması ve Model Parametrelerin Saptanmasi. TOAG 642. Ulưdağ Univ Ziraat Fak. Tarım Makineleri Bölümù Bursa.

Ciçek, G. 1997. Trakya Bölgesinde Tarım Makineleri Issletmecilig̈i Veri Tabanı. T.O. Fen Bilimleri Enstitüsü Tarım Makineleri Anabilim Dalt. Yüksek Lisans Tezi. Edirne

Dincer, H, 1976. Tarim isletmelerinde makine kullanma masraflari. Turkiye Zirai Donatim Kurumu Mesleki Yayınları. Ankara.

Işık, A. 1992. Doğrusal Programlama Tekniği ile Mekanizasyon Yatırımlarına Bağli Uretim Planlaması. Tarımsal Mekanizasyon 14. Ulusal Kongresi. 14-16 Ekim 1992. S. 463-473. Samsun.

Keskin R. ve D. Erdoğan, 1992. Tarımsal Mekanizasyon. Ankara Óniv. Ziraat Fak. Yayınlanı: Yayın No: 1254, Ders Kitabı No: 359. Ankara.

Parmar, R. S., R. W. McClendon and W. D. Potter, 1996. Farm Machinery Selection Using Similation and Genetic Algoritms. Transection of the ASAE. Vol. 39(5): 1905-1909.

Sindir, K. O. ve H. O. Evcim, 1989. Bir Işletme Örneğinde Mekanizasyon Gereksinimlerinin Doğrusal Programlama Modeli ile Belirlenmesi. Tarımsal Mekanizasyon 12. Ulusal Kongresi. S: 18-25, 1-2 Haziran 1989. Tekirdağ.

Ulusoy, E. ve H. A. Özbaydur, 1995. Değişik işletme Büyüklüklerinde Bilgisayar Destekli Mekanizasyon Planlaması. Tarımsal Mekanizasyon 16. Ulusal Kongresi. 57 Eylal 1995. Bursa.

Yakut, H. 1985. Doḡrusal Programlama Yardımi ile Işletme Biriminde Tarımsal Mekanizasyon Planlaması. Ege Oniv. Fen Bilimleri Enstitüsü Tarımsal Mekanizasyon Anabilim Dalı. Yüksek Lisans Tezi, Izmir.

Iletişim adresi:

Gıyaseltin ÇiÇEK

Trakya Üniv, Ziraat Fak. Tarım Makinaları Bölumü-Tekirdağ 